\title{
Ameliorative effects of Gentisic acid on carboplatin induced hematological toxicities in Wistar Rats
}

\author{
Rohini R. Pujari*, Deepti D. Bandawane
}

Modern college of Pharmacy, Yamunanagar, Nigdi, Pune-412105, Maharashtra, India.

\begin{abstract}
Hematological toxicity is a frequent and severe adverse effect of carboplatin chemotherapy, limiting its clinical use despite being one of the most potent anticancer agents. The present study was designed to evaluate the protective effects of a naturally occurring plant phenolic acids i.e. gentisic acid (2,5 dihyroxybenzoic acid) against carboplatin induced hematological toxicities in wistar rats. Exposure to carboplatin at a dose of $35 \mathrm{mg} / \mathrm{kg}$ caused significant decrease in hematological parameters of blood such as red blood cells, total leucocytes, platelets, neutrophills, basophills, lymphocytes and moncytes counts whereas increase in eosiphill counts rat blood indicating severe pancytopenia. Administration of gentisic acid at 10, 30 and 100 for 14 days resulted in a significant amelioration of altered blood parameters in a dose dependent manner indicating its potential as a protective agent for the prevention and amelioration of caboplatin induced hematological toxicities.

Key words : Gentisic acid; 2,5-Dihyroxybenzoic acid; Hematological toxicities; Carboplatin; Cancer chemotherapy; myelosuppression.
\end{abstract}

\section{Introduction:}

Cancer chemotherapy is associated with wide a range of side effects, adversely affecting patient health and quality of life. Myelosuppression remains the major toxicity encountered in the cytotoxic chemotherapy today leading to massive hypocellularity of the bone marrow by injuring hematopoitic progenitor stem cells resulting in depletion of red blood cells, white blood cells (leucopenia) and platelets (thrombocytopenia) thereby increasing the risk of anaemia, potentially fatal opportunistic infections, and uncontrolled hemorrhage, respectively, which proves to be life threatening to the patients. ${ }^{1-3}$ This in turn requires limiting the dosage and frequency of the drug to overcome these complications, decreased its efficacy. ${ }^{4}$

Carboplatin (cis-diammine [1,1-cyclobutanedicarboxylato]-platinum [II]), a new platinum complex is currently used in oncology clinics for the treatment of a variety of cancers such as ovarian cancer, lung cancer and head and neck cancer. The clinical use of carboplatin (CP) has been associated with various toxicities including nephrotoxicity, neurotoxicity and ototoxicity. One of the dose-limiting toxicities in patients receiving

Rohini R. Pujari et al /International Journal of PharmTech Research, 2019,12(3): 22-30.

DOI: http://dx.doi.org/10.20902/IJPTR.2019.120303 
$\mathrm{CP}$ has been reported as myelosuppression, mainly in the form of anaemia, thrombocytopenia and leucopenia. ${ }^{5-11}$ These hematological toxicities are manifested through different mechanism involving depression of hemopoiesis and enhanced lysis of blood corpuscles. ${ }^{12,13}$

Current scenario to overcome chemotherapy-induced myelosuppression includes few treatment modalities such as administration of growth factors, bone marrow transplantation, blood transfusion, but the procedures tend to be costly, complicated and painful with limited effectiveness in reversing the serious complications of myelosuppression. Hence alternative treatment with newer therapies with fewer side-effects and better efficacy is the need of the day. ${ }^{14,15}$

Use of active principles of medicinal plants for reducing the toxicities of cancer chemotherapeutic agents has been reported extensively. Most of the potent drugs used today in the treatment of major ailments are obtained from the plants in the form purely isolated or structurally modified compounds. ${ }^{16}$

Plant phenolic acids, secondary plant products are found in many fruits, nuts and vegetables are reported for their protective potential against cancer chemotherapy induced toxicities. ${ }^{17,18}$ Gentisic acid (GA) is a phenolic acid present in some plants such as olives, gentian, sesame, artichokes and various fruits including kiwi fruit, apple, bitter melon, blackberries, grapes, pears, and in aloe vera and mushrooms. ${ }^{19}$ It has been documented for its potential analgesic, anti-inflammatory, antimutagenic, antirheumatic, antiparkinsonian, antiarthritic, cytostatic, siderophoric and iron chelating activities. GA also possesses capability to inhibit lowdensity lipoprotein oxidation in human plasma documented in several studies. It has also been claimed to have an effective role in the anticarcinogenetic activity of China-rose hibiscus (Hibiscus rosa-sinensis) extract. ${ }^{20-22}$ Recently gentisic acid has shown its inhibitory activity against Fibroblast Growth Factor (FGF) and protective activity against cyclophospamide induced gentotoxicity and hepatototxicity. ${ }^{23,24}$

The present investigation was carried out to evaluate the protective activity of GA against CP induced hematological toxicities in wistar rats.

\section{Materials and methods}

\section{Chemicals and kits}

Gentisic acid was purchased from Sigma- Aldrich Chemicals Co., St. Louis, MO, USA. Carboplatin (Paraplatin) was purchased from GlaxoSmithKline Pharmaceuticals Ltd. Other chemicals and solvents used were of analytical grade and purchased from commercial suppliers. Heamcytometer, Sahli's heamoglobinometer for estimations of blood parameters were purchased from Kiran Enterprises, Pune, India.

\section{Experimental Animals}

Swiss albino mice weighing 25-30 g and wistar albino rats weighing (200-250g) were used. They were caged in a room under standard laboratory conditions (temperature $23 \pm 10{ }^{\circ} \mathrm{C}$, relative humidity $55 \pm 5 \%$ and lighting 08:00-20:00 h).The rats were fed on a pelleted diet (Nutrivet Lifesciences, Pune, India) and water ad libitum. The rats were transferred to the laboratory at least $1 \mathrm{~h}$ before the start of the experiment. The experiments were performed during day (08:00- 16:00 h).

\section{Ethical clearance}

All the studies were carried out in accordance with the guidelines given by the Committee for the Purpose of Control and Supervision of Experiments on Animals (CPCSEA), New Delhi (India) and the Institutional Animal Ethical Committee (IAEC) approved the study (Approval No.: 1036/RE/S/2007/CPCSEA/16-17/F-6).

\section{Preliminary acute oral toxicity testing}

Healthy adult albino mice were subjected to acute toxicity studies as per guidelines (AOT 425) suggested by the organization for economic co-operation and development (OECD-2000). The mice were 
observed continuously for $2 \mathrm{~h}$ for behavioral and autonomic profiles and for any sign of toxicity or mortality up to a period of seven days. ${ }^{25}$

\section{Treatment protocol}

Animals were divided in six groups, each containing six animals $(n=6)$.

Group I (Normal Control): The animals were given distilled water $(2 \mathrm{ml} / \mathrm{kg}$ b.w./day), parallel to the drug treated groups, throughout the course of the study of 15 days.

Group II (CP control group): The animals first received distilled water $(1 \mathrm{ml} / \mathrm{kg}$ b.w./day) by oral route for 9 days, and subsequently received CP (35 $\mathrm{mg}$ in $1 \mathrm{ml}$ normal saline per $\mathrm{kg} \mathrm{b.w.)} \mathrm{once} \mathrm{daily} \mathrm{by} \mathrm{intraperitoneal}$ injection in association with normal saline for additional 5 days.

Group III (CP + GA 3): The animals first received GA alone at a dose of (3 mg/kg b.w./day) by oral intubation for 9 days, and subsequently received CP $(35 \mathrm{mg} / \mathrm{kg}$ b.w./day) by intraperitoneal injection in association with GA (3 mg/kg b.w./day) for additional 5 days.

Group IV (CP + GA 10): The animals first received GA alone at a dose of (10 mg/kg b.w./day) by oral intubation for 9 days, and subsequently received $\mathrm{CP}(35 \mathrm{mg} / \mathrm{kg}$ b.w./day) by intraperitoneal injection in association with GA (10 mg/kg b.w./day) for additional 5 days.

Group V (CP + GA 30): The animals first received GA alone at a dose of (30 mg/kg b.w./day) by oral intubation for 9 days, and subsequently received CP $(35 \mathrm{mg} / \mathrm{kg}$ b.w./day) by intraperitoneal injection in association with GA (30 mg/kg b.w./day) for additional 5 days.

Group VI (CP + GA 100): The animals first received GA alone at a dose of (100 mg/kg b.w./day) by oral intubation for 9 days, and subsequently received CP $(35 \mathrm{mg} / \mathrm{kg}$ b.w./day) by intraperitoneal injection in association with GA (100 mg/kg b.w./day) for additional 5 days.

\section{Blood Sample collection}

At the end of the experimental period, blood was withdrawn from retro orbital plexus and transferred into a sterile EDTA container.

\section{Estimation of hematological parameters}

Estimation of red blood cell (RBC) counts

The RBC counts were determined following the method of Raghuramulu, Madhavan, \& Kalyansundaram, 1983, using Neubaeurs chamber. ${ }^{26}$

Estimation of total leukocyte counts (TLC)

The TLC counts were determined following the method of Raghuramulu, Madhavan, \& Kalyansundaram, 1983 using Neubaeurs chamber. ${ }^{21}$

Estimation of differential leucocyte counts (DLC) chamber. $^{27}$

The DLC counts were determined following the method of Dacie \& Lewis, 1984 using Neubaeurs

Estimation of hemoglobin content

The RBC contents were determined following the method of Varley, 2005 using Sahli Helige's hemoglobinometer. ${ }^{28}$

Estimation of platelet count chamber. $^{29}$

The platelet counts were determined following the method of Samuel, 1986 using Neubaeurs 


\section{Statistical analysis}

The results were expressed as mean \pm SEM. Comparison between the groups was made by one way analysis of variance (ANOVA) followed by Tukey's Kramer Multiple Comparison test *,\#-P<0.05, **,\#\#$\mathrm{P}<0.01$, ***,\#\#\#-P<0.001; *-Normal Control group with CP induction control group; \#- GA treated groups against carboplatin induction control group.

\section{Results}

\section{Estimation of RBC counts}

Treatment with $\mathrm{CP}$ produced a significant $(\mathrm{P}<0.001)$ decrease in the $\mathrm{RBC}$ counts of $\mathrm{CP}$ control group as compared to normal control group, $\mathrm{CP}$ groups co-treated with GA (10, 30 and $100 \mathrm{mg} / \mathrm{kg})$ showed significantly $(\mathrm{P}<0.05, \mathrm{P}<0.01$ and $\mathrm{P}<0.001)$ increased the $\mathrm{RBC}$ counts in a dose dependent manner in comparison with $\mathrm{CP}$ control group rats. The dose $3 \mathrm{mg} / \mathrm{kg}$ was found to be ineffective in this regard (Table 1).

\section{Estimation of total leukocyte counts (TLC)}

TLC counts of CP control group were significantly $(\mathrm{P}<0.001)$ lowered as compared to normal control group. Co-treatment of GA $(10,30$ and $100 \mathrm{mg} / \mathrm{kg})$ with $\mathrm{CP}$ produced a significant $(\mathrm{P}<0.05, \mathrm{P}<0.01$ and $\mathrm{P}<0.001)$ and dose dependant increase in the TLC counts in comparison with CP control group rats. The dose 3 $\mathrm{mg} / \mathrm{kg}$ was found to be ineffective in this regard (Table 1).

\section{Estimation of differential leucocyte counts (DLC)}

There was significant $(\mathrm{P}<0.001)$ increase in the eosinophil counts whereas significant decrease in basophils $(\mathrm{P}<0.01)$, neutrophils $(\mathrm{P}<0.001)$, lymphocytes $(\mathrm{P}<0.001)$ and monocytes $(\mathrm{P}<0.01)$ counts in carboplatin induced control group animals as compared normal control group animals. Co-treatment of GA (10, 30 and $100 \mathrm{mg} / \mathrm{kg}$ ) with $\mathrm{CP}$ produced significant $(\mathrm{P}<0.05, \mathrm{P}<0.01$ and $\mathrm{P}<0.001)$ reduction in eosinophil count and significantly $(\mathrm{P}<0.05, \mathrm{P}<0.01$ and $\mathrm{P}<0.001)$ increased the basophils, neutrophils, lymphocytes and monocytes in a dose dependant manner as compared to CP control group. The dose $3 \mathrm{mg} / \mathrm{kg}$ was found to be ineffective in this regard (Table 1).

\section{Estimation of hemoglobin (Hb) content}

Treatment with CP produced a significant $(\mathrm{P}<0.001)$ decrease in the $\mathrm{Hb}$ contents of $\mathrm{CP}$ control group as compared to normal control group, CP groups co-treated with GA $(10,30$ and $100 \mathrm{mg} / \mathrm{kg})$ showed significantly $(\mathrm{P}<0.05, \mathrm{P}<0.01$ and $\mathrm{P}<0.001)$ increased the $\mathrm{Hb}$ contents in a dose dependent manner in comparison with $\mathrm{CP}$ control group rats. The dose $3 \mathrm{mg} / \mathrm{kg}$ was found to be ineffective in this regard (Table 1).

\section{Estimation of platelet counts}

Platelet counts of $\mathrm{CP}$ control group were significantly $(\mathrm{P}<0.001)$ lowered as compared to normal control group. Co-treatment of GA $(10,30$ and $100 \mathrm{mg} / \mathrm{kg})$ with $\mathrm{CP}$ produced a significant $(\mathrm{P}<0.05, \mathrm{P}<0.01$ and $\mathrm{P}<0.001)$ and dose dependant increase in the TLC counts in comparison with CP control group rats. The dose 3 $\mathrm{mg} / \mathrm{kg}$ was found to be ineffective in this regard (Table 1). 
Table 1: Effect of CP and GA on hematological parameters

\begin{tabular}{|c|c|c|c|c|c|c|c|c|c|}
\hline Groups & $\begin{array}{c}\text { RBCs } \\
\left(\text { Million } / \mathbf{m m}^{3}\right)\end{array}$ & $\begin{array}{c}\text { TLC } \\
\left(/ \mathbf{m m}^{3}\right)\end{array}$ & $\begin{array}{c}\text { Eosinophills } \\
(\%)\end{array}$ & $\begin{array}{c}\text { Basophills } \\
(\%)\end{array}$ & $\begin{array}{c}\text { Neutrophills } \\
(\%)\end{array}$ & $\begin{array}{c}\text { Lymphocytes } \\
(\%)\end{array}$ & $\begin{array}{c}\text { Monocytes } \\
(\%)\end{array}$ & $\begin{array}{l}\text { Hb count } \\
(\mathrm{g} \%)\end{array}$ & $\begin{array}{c}\text { Platelet } \\
\left(\text { Lakhs } / \mathbf{~ m m}^{3}\right)\end{array}$ \\
\hline $\begin{array}{l}\text { Normal } \\
\text { Control }\end{array}$ & $6.63 \pm 0.08$ & $7100 \pm 22.80$ & $1.08 \pm 0.02$ & $2.97 \pm 0.18$ & $61.76 \pm 5.34$ & $32.90 \pm 4.11$ & $7.01 \pm 2.05$ & $14.8 \pm 0.17$ & $3.57 \pm 0.05$ \\
\hline CP Control & $3.23 \pm 0.05 * * *$ & $2750 \pm 9.87 * * *$ & $6.76 \pm 0.25 * * *$ & $1.16 \pm 0.02 * *$ & $31.65 \pm 6.35 * * *$ & $15.44 \pm 6.21 * * *$ & $3.45 \pm 1.56^{* *}$ & $7.51 \pm 0.15 * * *$ & $1.45 \pm 0.03 * * *$ \\
\hline GA $3+$ CP & $3.66 \pm 0.07$ & $2820 \pm 11.28$ & $6.56 \pm 0.18$ & $1.09 \pm 0.04$ & $39.43 \pm 5.67$ & $19.45 \pm 5.11$ & $3.77 \pm 1.52$ & $6.98 \pm 0.12$ & $1.36 \pm 0.01$ \\
\hline GA $10+C P$ & $4.85 \pm 0.06^{\#}$ & $4800 \pm 10.25^{\#}$ & $3.98 \pm 0.08^{\#}$ & $1.92 \pm 0.02^{\#}$ & $42.67 \pm 4.21^{\#}$ & $25.37 \pm 4.89^{\#}$ & $4.97 \pm 2.33^{\#}$ & $10.03 \pm 0.16^{\#}$ & $2.55 \pm 0.05^{\#}$ \\
\hline GA 30 + CP & $6.01 \pm 0.06^{\# \#}$ & $5803 \pm 12.39^{\# \#}$ & $3.04 \pm 0.04^{\# \#}$ & $2.55 \pm 0.01^{\# \#}$ & $55.11 \pm 5.72^{\# \#}$ & $31.25 \pm 4.33^{\# \#}$ & $5.80 \pm 2.66^{\# \#}$ & $11.20 \pm 0.19^{\# \#}$ & $2.89 \pm 0.03^{\# \#}$ \\
\hline GA $100+C P$ & $6.55 \pm 0.08^{\# \# \# ~}$ & $7021 \pm 13.21^{\# \# \#}$ & $1.55 \pm 0.02^{\# \# \#}$ & $3.45 \pm 0.04^{\# \# \#}$ & $62.23 \pm 6.45^{\# \# \#}$ & $33.27 \pm 2.48^{\# \# \#}$ & $7.67 \pm 3.12^{\# \#}$ & $13.85 \pm 0.20^{\# \# \#}$ & $4.01 \pm 0.087^{\# \# \#}$ \\
\hline
\end{tabular}

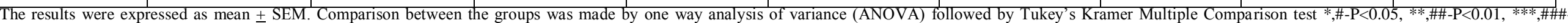
$\mathrm{P}<0.001$; *-Normal Control group with $\mathrm{CP}$ induction control group; \#- GA treated groups against CP induction control group. 


\section{Discussion}

Cancer chemotherapy induced hematological disorders have been reports to span almost the entire spectrum of hematology, affecting red cells, white cells, platelets, and the coagulation system. These hematologic abnormalities induced by chemotherapeutic agents are mediated by different mechanisms, including inhibition of hematopoiesis due to mild to moderate suppression of bone marrow, immunological effects and altered enzymatic pathways. ${ }^{30}$

Carboplatin, a platinum complex has shown prominent antitumour activity against a number of human cancers but the major dose-limiting toxicity of this analog is reported to be hematological toxicities. ${ }^{31}$ The present investigation was aimed to assess the alterations produced by the $\mathrm{CP}$ on hematological parameters in rats and effect of a plant phenolic acid GA on these alterations taking in consideration its wide range of pharmacological activities documented previously. ${ }^{19-24}$

It has been reported in the earlier clinical studies that patients treated with platinum compounds have a higher chances of severe anemia. ${ }^{32}$ In the present study the administration of CP resulted into significant decrease in the RBC counts as well as heamoglobin content of blood in the $\mathrm{CP}$ control rats as compared to normal rats indicated severe anemic condition. These results were in accordance with the previous findings. The co-treatment with GA at the doses 10,30 and $100 \mathrm{mg} / \mathrm{kg}$ showed a significant protection against these alterations as compared to $\mathrm{CP}$ control group indicating anti-anemic activity of GA against $\mathrm{CP}$ induced anemia. GA has been reported for its iron chelating properties which have been proved to be useful in the treatment of thalassemic patients. ${ }^{33,34}$ It has also been reported for being an endogenous siderophore whose deficiency may lead to anemia and splenic overload in mice. ${ }^{35}$ These reports may be correlated in this study wherein the CP induced anemia has been successfully ameliorated which can be attributed to the iron chelating properties of GA. Huang et al., 2011 in their study documented the association between the grade of platinum-based chemotherapy induced leukopenia and the clinical outcome of patients with metastatic non-small cell lung cancer patients amongst which neutropenia and monocytopenia was found to be more prominent. ${ }^{36}$ Few other studies reported the lymphocytopenia and basocytopenia associated with platinum based chemotherapeutic agents. ${ }^{37,38}$ Chemotherapy induced neutropenia is a life-threatening and serious adverse effect that may lead to a high risk of developing serious complications such as pyrexia associated with severe or life-threatening infections. It found more frequently in immunocompromised and vulnerable elderly patients resulting in the fatal outcome. ${ }^{39,40}$ Basopenia (or basocytopenia), characterized by a deficiency of basophils is one of the major hematological adverse effects of antineoplastic drugs increasing the vulnerability of patients towards severe infections. ${ }^{41}$ A recently evidenced study showed that the chemotherapy-induced leucocytosis results into severe lymphopenia that may modify the immune milieu of a patient by depleting regulatory cells and endogenous cells that compete for activating cytokines. ${ }^{42}$ Platinum based chemotherapy induced monocytopenia is a form of leukocytopenia associated with a deficiency of monocytes resulting from apoptosis induced by cross linking of monocyte DNA ${ }^{43}$ In an investigation by Kondo et al., 1999 identified that monocytopenia after chemotherapy proves to be a risk factor for neutropenia and associated consequences. ${ }^{44}$

In our study $\mathrm{CP}$ treatment for 5 days induced significant decrease in the nuetrophil, basophill, lymphocyte and monocyte count indicating severe leucocytoenia induced by $\mathrm{CP}$ and the results were found to be in accordance with previous reports. Co-treatment with GA at doses of 10,30 and $100 \mathrm{mg} / \mathrm{kg}$ exhibited a significant attenuation of neutropenia, basocytopenia, lymphocytopenia and monocytopenia caused by CP by significantly increasing their counts respectively; indicating protective effect of GA against CP induced leucocytopenia.

Although all the leukocytes counts were found to be decreased but there was significant increased in the eosinophill count indicative of allergic manifestations induced by $\mathrm{CP}$ which was in agreement with the earlier studies documented. ${ }^{45}$ GA $(10,30$ and $100 \mathrm{mg} / \mathrm{kg})$ was successful in normalizing the eosinophill counts showing its capability to treat the CP induced hypersensitivity reactions. Thrombocytopenia induced by cancer chemotherapy is a major complication which can cause delay or reduction in subsequent courses of chemotherapy. As reported in literature thrombocytopenia occurred in $82 \%$ of those receiving only carboplatin leading to severe hemorrhage. ${ }^{46,47}$ The thrombocyte counts in CP control group were found to be significantly reduced as compared to the normal control group indicating $\mathrm{CP}$ induced thrombocytopenia in similarity to the previous reports. Co-treatment with GA $(10,30$ and $100 \mathrm{mg} / \mathrm{kg})$ significantly prevented the decrease in thrombocyte counts and showed normalized counts as compared to $\mathrm{CP}$ control group indicating its potential 
protective action against thrombocytopenia. Siddik et al., 1987 in their studies found that the dose-limiting toxicity, anaemia caused by carboplatin appears to be a secondary effect of thrombocytopenia. ${ }^{13}$ Hence the antianemic effect of GA can also be attributed to its ameliorative effect against CP induced thrombocytopenia. In the whole study $3 \mathrm{mg} / \mathrm{kg}$ of GA was found to be ineffective in treating CP induced hematological toxicities.

\section{Conclusion}

In conclusion GA may be considered as a potential natural phenolic agent that can be used to protect and ameliorate the hematological adverse effects, such as anemia, leucocytopenia and thrombocytopenia induced by $\mathrm{CP}$. These protective effects can be attributed to attenuation of myelosupression. Further studies are required to reveal the possible molecular mechanisms involved in protective effects of GA.

\section{Acknowledgement}

Authors are grateful to Dr. P. D. Chaudhari, Principal, Modern College of Pharmacy, Nigdi, Pune for providing facilities guidance and support.

\section{References}

1. Testart-Paillet D, Girard P, You B, Freyer G, Pobel C, Tranchand B. Contribution of modelling chemotherapy-induced hematological toxicity for clinical practice. Crit Rev Oncol Hematol. 2007;63:1-11.

2. Dale DC, McCarter GC, Crawford J, Lyman GH. Myelotoxicity and dose intensity of chemotherapy: Reporting practices from randomized clinical trials. J Natl Compr Cancer Netw. 2003;1:440-54.

3. Barreto JN, McCullough KB, Ice LL, Smith JA, Antineoplastic agents and the associated myelosuppressive effects: A review. J Pharm Pract. 2014;27:440 - 446.

4. Repetto L. Incidence and clinical impact of chemotherapy induced myelotoxicity in cancer patients: an observational retrospective survey. Crit Rev Oncol Hematol. 2009;72:170-9.

5. Calvert AH, Harland SJ, Newell DR et al. Early clinical studies with cis-diammine- 1,1 -cyclobutane dicarboxylate platinum II. Cancer Chemother Pharmacol. 1982;9:140.

6. Gridelli C, Manzione L, Perrone F, Veltri E, Cid R, Caprio M.G. et al. Carboplatin plus paclitaxel in intensive small cell lung cancer: a multicenter phase 2 study. Br J Cancer. 2001;84:38-41.

7. Bolis G, Scarfone G, Tateo S, Mangili G, Villa A, Parazzini F. Response and toxicity to topotecan in sensitive in sensitive ovarian cancer cases with small residual disease after $\phi$ rst line treatment with carboplatinum and paclitaxel. Gynecol Oncol. 2001:80:13-15.

8. Meyer WH, Pratt CB, Poquette CA, Rao BN, Parham DM, Marina, N.M., et al. Carboplatin/ifosfomide window therapy for osteosarcoma: results of the St. Jude children's hospital OS-91 trial. J Clin Oncol. 2001;19:171-182.

9. Ettinger DS. The role of carboplatin in the treatment of small-cell lung cancer. Oncology (Huntingt.) 1998;12:36-43.

10. Pivot X, Cals L, Cupissol D, Guardiola E, Tchiknavorian X, Guerrier P et al. Phase II trial of a paclitaxel-carboplatin combination in recurrent squamous cell carcinoma of the head and neck. Oncology. 2001;60:66-71.

11. Harrap KR, Jones M, Wilkinson CR et al. Antitumour, toxic and biochemical properties of cis-platin and eight other platinum complexes. In Cis-platin: Current Status and New Developments, (eds.) Prestayko AW et al. Academic Press, New York 1980:193.

12. Getaz EP, Beckley S, Fitzpatrick J, Dozier A. Cis-platin-induced haemolysis. N. Engl J Med. 1980;302:334.

13. Siddik ZH, Boxall FE, Harrap KR. Haematological toxicity of carboplatin in rats. Br J Cancer. 1987;55:375-379.

14. Trueman P. Prophylactic G-CSF in patients with early-stage breast cancer: a health economic review. Br J Cancer. 2009;101 Suppl:S15-7..

15. Ghidini M, Hahne JC, Trevisani F, Panni S, Ratti M, Toppo L, Tomasello G, New developments in the treatment of chemotherapy-induced neutropenia: Focus on balugrastim. Ther Clin Risk Manag. 2016;12:1009-1015.

16. De Smet PA. Herbal Remedies. Review article. N Engl J Med. 2002;347:2046-2056. 
17. Crozier A, Jaganath IB, Clifford MN. Dietary phenolics: Chemistry, bioavailability and effects on health. Nat Prod Rep. 2009;26:1001-1043.

18. Harris CS, Mo F, Migahed L, Chepelev L, Haddad PS, Wright JS et al. Plant phenolics regulate neoplastic cell growth and survival: a quantitative structure-activity and biochemical analysis. Can J Physiol Pharmacol. 2007;85:1124-1138.

19. Stochmal A, Kowalska I, Janda B, Perrone A, Piacente S, Oleszek W. Gentisic acid conjugates of Medicago truncatula roots. Phytochemistry. 2009;70:1272-1276.

20. Cunha JF, Campestrini FD, Calixto JB, Scremin A, Paulino N. The mechanism of gentisic acid-induced relaxation of the guinea pig isolated trachea:the role of potassium channels and vasoactive intestinal peptide receptors. Braz J Med Biol Res. 2001;34(3):381-388.

21. Ashidate K, Kawamura M, Mimura D, Tohda H, Miyazaki S. Teramoto T et al.. Gentisic acid, an aspirin metabolite, inhibits oxidation of low-density lipoprotein and the formation of cholesterol ester hydroperoxides in human plasma. Eur J Pharmacol. 2005;513:173-179.

22. Sharma S, Khan N, Sultana S. Study on prevention of two-stage skin carcinogenesis by Hibiscus rosa Sinensis extract and the role of its chemical constituent, gentisic acid, in the inhibition of tumour promotion response and oxidative stress in mice. Eur J Cancer Prev 2004;13:53-63.

23. Fernandez IS, Cuevas P, Angulo J, Lopez-Navajas P, Canales-Mayordomo A, Gonzalez-Corrochano R et al. Gentisic Acid, a Compound Associated with Plant Defense and a Metabolite of Aspirin, Heads a New Class of in vivo Fibroblast Growth Factor Inhibitors. J Biol Chem. 2010;285:11714-11729.

24. Sana N, Shiekh TA, Wani A, Summya R, Nemat A, Sarwat S. Modulatory effects of gentisic acid against genotoxicity and hepatotoxicity induced by cyclophosphamide in Swiss albino mice. 2011;64:259-267.

25. OECD Guideline For The Testing of Chemicals: Guidance document on acute oral toxicity. Environmental Health and Safety Monograph Series on Testing and Assessment 2000.

26. Raghuramulu N. Madharan N. Kalyansundaram S. A manual of laboratory techniques. Hyderabad: Silver prints. 1983;78:257-258.

27. Dacie J, Lewis S. Practical Hematology. NewYork, NY: Churchill-Lingstone Edinburgh 1984, 84-86.

28. Varley H. Practical Clinical Biochemistry (4th ed.). New Delhi: CBC Publisher and distributor 2005.

29. Samuel KM. Notes on clinical lab techniques. Madras: MGK Iyyer and Sons Publishers 1986,168.

30. Carey PJ. Drug-induced myelosuppression: diagnosis and management. Drug Saf. 2003;26:691706.

31. Fujiwara K, Markman M, Morgan M, Robert L. Coleman, intraperitoneal carboplatin-based chemotherapy for epithelial ovarian cancer. Gynecol. Oncol. 2005;97 (1):1-15.

32. Lebwohl D, Canetta R. Clinical development of platinum complexes in cancer therapy: an historical perspective and an update. Eur J Cancer 1998;34:1522-1534.

33. Liu Z, Reba S, Chen WD, Porwal SK, Boom WH, et al. Regulation of mammalian siderophore 2,5DHBA in the innate immune response to infection. J Exp Med. 2014;211(6):1197-1213.

34. Kukreja A, Wadhwa N, Tiwari A. Therapeutic role of natural agents in beta-thalassemia: A review. J Pharm Res. 2013;6:954-9.

35. Liu Z, Ciocea A, Devireddy L. Endogenous siderophore 2,5-dihydroxybenzoic acid deficiency promotes anemia and splenic iron overload in mice. Mol Cell Biol. 2014a Jul;34(13):2533-2546.

36. Huang A, Ma M, Jin B, Han B. Chemotherapy-induced leukopenia as a prognostic factor in patients with metastatic non-small cell lung cancer treated with platinum-based chemotherapy. Int J Clin Exp Med 2016;9:5241-5248.

37. Khynriam D, Prasad SB. Hematotoxicity and blood glutathione levels after cisplatin treatment of tumor-bearing mice. Cell Biol Toxicol. 2001;17(6):357-70.

38. Blay JY, Chauvin F, Le Cesne A, et al. Early lymphopenia after cytotoxic chemotherapy as a risk factor for febrile neutropenia. J Clin Oncol 1996;14:636-43.

39. Jodrell DI, Egorin MJ, Canetta RM, Langenberg P, Goldbloom EP, Burroughs JN et al. Relationships between carboplatin exposure and tumor response and toxicity in patients with ovarian cancer. J Clin Oncol. 1992;10 (4):520-528.

40. Repetto L. Greater risks of chemotherapy toxicity in elderly patients with cancer. J Support Oncol. 2003;4(2):18-24.

41. Molyneux G, Andrews M, Sones W, York M, Barnett A, Quirk E, et al. Haemotoxicity of busulphan, doxorubicin, cisplatin and cyclophosphamide in the female BALB/c mouse using a brief regimen of drug administration. Cell Biol Toxicol. 2011;27:13-40. 
42. Zhang QH, Wu CF, Duan L, Yang JY. Protective effects of total saponins from stem and leaf of Panax ginseng against cyclophosphamide-induced genotoxicity and apoptosis in mouse bone marrow cells and peripheral lymphocyte cells. Food Chem Toxicol. 2008;46:293-302.

43. Oguz A, Karadeniz C, Ckitak EC, Cil V. Which one is a risk factor for chemotherapy induced febrile neutropenia in childhood solid tumors: Early lymphopenia or monocytopenia. Pediatr Hematol Oncol. 2006;23(2):143-151.

44. Kondo M, Oshita F, Kato Y, Yamada K, Nomura I, Noda K. Early monocytopenia after chemotherapy as a risk factor for neutropenia, Am J Clin Oncol. 1999;22:103-105.

45. Markman M, Zanotti K, Kulp B, Peterson G, Markman M. Relationship between a history of systemic allergic reactions and risk of subsequent carboplatin hyper- sensitivity. Gynecol Oncol. 2003;89(3):514-516.

46. Maxwell MB, Maher KE. Chemotherapy- induced myelosuppression. Semin Oncol Nurs. 1992;8:11323.

47. Iuliano F, Santoro M, Iuliano E, Luci M, Pomillo A, Perricelli A. Eltrombopag low doses as prophilaxis of Chemotherapy-induced thrombocytopenia (CIT) in cancer patients treated with platinum based chemotherapy Annals Oncol. 2016;27(4):122-123. 